\title{
Transport mechanisms of contaminants released from fine sediment in rivers
}

\author{
Pengda Cheng ${ }^{1,2} \cdot$ Hongwei Zhu' ${ }^{2}$ B Baochang Zhong² • Daozeng Wang
}

Received: 30 June 2014 / Revised: 13 November 2014 / Accepted: 30 January 2015 / Published online: 22 September 2015

(C) The Chinese Society of Theoretical and Applied Mechanics; Institute of Mechanics, Chinese Academy of Sciences and Springer-Verlag Berlin Heidelberg 2015

\begin{abstract}
Contaminants released from sediment into rivers are one of the main problems to study in environmental hydrodynamics. For contaminants released into the overlying water under different hydrodynamic conditions, the mechanical mechanisms involved can be roughly divided into convective diffusion, molecular diffusion, and adsorption/desorption. Because of the obvious environmental influence of fine sediment $\left(D_{90}=0.06 \mathrm{~mm}\right)$, non-cohesive fine sediment, and cohesive fine sediment are researched in this paper, and phosphorus is chosen for a typical adsorption of a contaminant. Through theoretical analysis of the contaminant release process, according to different hydraulic conditions, the contaminant release coupling mathematical model can be established by the N-S equation, the Darcy equation, the solute transport equation, and the adsorption/desorption equation. Then, the experiments are completed in an open water flume. The simulation results and experimental results show that convective diffusion dominates the contaminant release both in non-cohesive and cohesive fine sediment after their suspension, and that they contribute more than $90 \%$ of the total release. Molecular diffusion and desorption have more of a contribution for contaminant release from unsuspended sediment. In unsuspension sediment, convective diffusion is about 10-50 times larger than molecular diffusion during the initial stages under high velocity; it is close to molecular diffusion in the later stages. Convective diffusion is about 6 times larger than molecular diffusion during the
\end{abstract}

Daozeng Wang

dzwang@staff.shu.edu.cn

1 Institute of Mechanics, Chinese Academy of Sciences, Beijing 100190, China

2 Shanghai Institute of Applied Mathematics and Mechanics, Shanghai University, Shanghai 200072, China initial stages under low velocity, it is about a quarter of molecular diffusion in later stages, and has a similar level with desorption/adsorption. In unsuspended sediment, a seepage boundary layer exists below the water-sediment interface, and various release mechanisms in that layer mostly dominate the contaminant release process. In non-cohesive fine sediment, the depth of that layer increases linearly with shear stress. In cohesive fine sediment, the range seepage boundary is different from that in non-cohesive sediment, and that phenomenon is more obvious under a lower shear stress.

Keywords Cohesive - Diffusion - Seepage boundary layer $\cdot$ Adsorption/desorption $\cdot$ Coupling

\section{Introduction}

The complex exchange processes of substances like nutrients, persistent organic pollutants (POPs), heavy metals, and other potentially harmful materials between the contaminated sediment and the overlying water column in rivers, lakes, reservoirs, and estuaries are of considerable importance in understanding the impacts of the contaminated sediment on the aquatic environments [1-3]. It is well known that the transport process across the sediment-water interface in the case of the static release is dominated by the direct diffusion process, and there exists a diffusive boundary layer within which the mass transfer of the contaminants occurs largely due to molecular diffusion or convective diffusion [4]. This diffusive process is likely to cause an increasing contaminant concentration of the overlying water column even after those externally supplied contaminant sources have been removed or heavily reduced, and the associated diffusion flux 


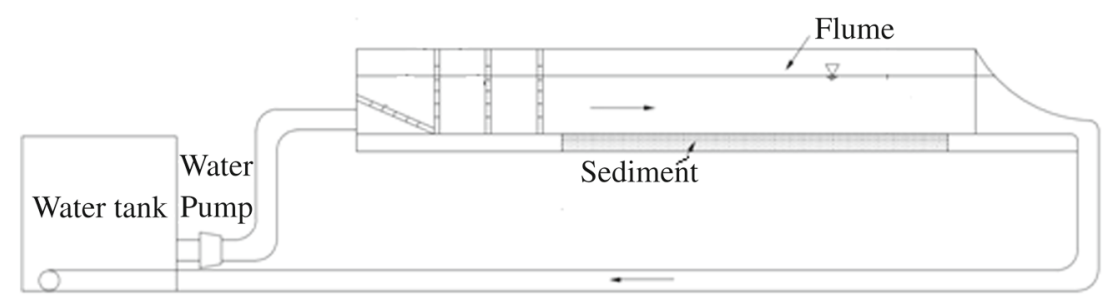

Fig. 1 Experimental water flume

Table 1 The experimental parameters of natural sediment under $10 \mathrm{~g} / \mathrm{l}$

\begin{tabular}{llllll}
\hline Initial concentration $(\mathrm{mg} / \mathrm{l})$ & 3 & 5 & 7 & 10 & 12 \\
\hline Equilibrium concentration (mg/l) & 0.302 & 0.962 & 1.966 & 3.506 & 4.895 \\
Adsorption of sediment (mg/g) & 0.269 & 0.401 & 0.501 & 0.648 & 0.709 \\
\hline
\end{tabular}

can commonly be estimated based on the measured concentration gradient across the sediment-water interface [5].

Most experimental studies in recent years have focused on static release [6-8]. Because of the incompleteness of the static release research, contaminated sediment released under hydrodynamic conditions is a growing area of focus. Laboratory experiments such as oscillating grids [9], annular tanks and open water channels have been conducted to study the contaminated sediment release regularly under conditions of flowing water [10,11]. By using the annular tank test, the law of sediment suspension and release were simulated by different disturbance forces [12-14].

For the adsorptive contaminants, the adsorption/desorption behaviors of the sediment play an important role in the transport process across the sediment-water interface[1517]. In this article, the phosphorus $(\mathrm{P})$ adsorption isotherms and artificial sediment samples are examined in sediment suspension experiments. The $\mathrm{P}$ desorption and release features from the sediment layer are then experimentally investigated under different hydrodynamic conditions. Because of the obviously environmental influence of fine sediment ( $\left.D_{90}=0.06 \mathrm{~mm}\right)$, non-cohesive fine sediment, and cohesive fine sediment are researched in this paper. Through theoretical analysis of the contaminant release process, the contaminant release coupling mathematical model can be established by the $\mathrm{N}-\mathrm{S}$ equation, the Darcy equation, the solute transport equation and the adsorption/desorption equation [18-20]. The characteristics of contaminant release from sediment to overlying water are experimentally and numerically investigated under different flow velocities.

\section{Experiment}

\subsection{Experimental flume}

The experiments are carried out in an open flume with a rectangular test section of $2.5 \mathrm{~m}$ in length, $0.2 \mathrm{~m}$ in width, and $0.4 \mathrm{~m}$ in height. The overlying re-circulated water of the channel is supplied from a rectangular water tank of $1.5 \mathrm{~m}^{3}$ volume. The required water flow velocity $(0.05-0.15 \mathrm{~m} / \mathrm{s})$ and water depth $(H=0.1 \mathrm{~m})$ of the overlying water-body are attained by suitably adjusting both the rotating speed of a frequency-controlled centrifugal water pump and the opening of a tail gate located at the end of the channel flume. A diagram of the experimental setup is shown in Fig. 1.

During the flume experiments, three sampling sections of the water samples are sent downstream from the inlet of the flume, and seven sampling points at heights of 0.005 $0.1 \mathrm{~m}$ above the sediment-water interference were arranged in each section. Dissolved total phosphorus (DTP) concentration in the overlying water could be measured in the laboratory under different flow velocities. LDA/LDV is used to measure and supervise the velocity of water flow. In the experiment, the release properties of the contaminants in sediments change with time and could be determined from the measured contaminant concentrations $\mathrm{C}(\mathrm{mg} / \mathrm{l})$ of the overlying water column. The samples are filtered through a $0.45 \mu \mathrm{m}$ $\mathrm{GF} / \mathrm{C}$ membrane, and analyzed by using the molybdenum blue/ascorbic acid method (GB11893-89) for DTP.

\subsection{Measurements}

In general, the contaminant adsorption/desorption characteristics of the sediment depends on numerous interacting physical, biochemical, and environmental factors, among which the physical properties of the sediment are the main influencing factors under consideration in this article [21]. The adsorption/desorption isotherms for different particlesized sediment suspensions are the fundamental properties that greatly affect the contaminant transport process [22]. In the present adsorption experiment, the $\mathrm{P}$ adsorption isotherms for sediments were measured and obtained at specific initial aqueous concentrations $C_{0}$ as shown in Table 1 $[23,24]$. The obtained experimental data in terms of the 
Table 2 The fitted parameters of the Langmuir equation

\begin{tabular}{llll}
\hline$D_{90}(\mathrm{~mm})$ & $S$ & $K_{2}$ & $R^{2}$ \\
\hline 0.06 (Natural) & 0.793 & 1.198 & 0.9705 \\
0.05 (Artificial) & 0.086 & 0.092 & 0.98 \\
0.1 (Artificial) & 0.031 & 1.718 & 0.965 \\
0.2 (Artificial) & 0.028 & 2.299 & 0.917 \\
\hline
\end{tabular}

adsorption quantity and the aqueous equilibrium concentration of all cases fit well with the Langmuir equation.

The $\mathrm{P}$ adsorption isotherms for natural and artificial sediment suspensions exhibit similar overall trends, indicating that the increasing initial concentration leads to the increasing adsorption quantity of the unit weigh sediments. The obtained data fit well with the Langmuir equation as shown in Table 2, and the measured adsorption quantity of the natural sediment is shown to be higher in magnitude than that of the artificial sediment. This is predominantly attributed to the fine grain size and, thus, larger specific surface area for the natural sediment. The effect of the sediment content on the adsorption quantity is taken into account in a wide range of the suspension sediment concentrations, and the measured adsorption quantities of different grain-sized sediments in suspension are analyzed respectively. For fine sediment, there exists a maximum adsorption quantity under the experimental conditions. While for the relatively coarse sediment, there also exists a maximum adsorption quantity in magnitude at the appreciably lower peak as compared to that in fine sediment. Therefore, it can be inferred that it is indispensable to comprehensively take the effect of the grain size and sediment content on the adsorption property into consideration. The fine sediment has a more obvious environmental effect; its grain size is normally from 0 to $0.06 \mathrm{~mm}$, and the maximum sorption $(S)$ is $0.793 \mathrm{mg} / \mathrm{g}$, the adsorption coefficient $(K)$ is 1.198 , and the correlation coefficient of the fitting parameters is 0.985 .

In this study, the release mechanisms of pollutants from sediment are first researched by the flume experiment. The sediment contains solid particles in particulate phase and pore water in dissolved phase, which indicates two different kinds of release mechanisms in solid phase and water phase, respectively, from particles and pore water. During the initial resuspension, release flux mainly comes from the desorption from suspended particles and convective diffusion from pore water; in the middle of resuspension, sediment particles change from desorption of contaminants to adsorbed while convective diffusion plays the dominant role at this time. For the long-term release, desorption still occurs because of the cohesive sediment. As shown in Fig. 2, the particle concentration of the resuspension sediment goes up with increasing velocity, and it rapidly increases after $V>0.10 \mathrm{~m} / \mathrm{s}$. That phenomenon can be regarded as sediment resuspension. Fur-

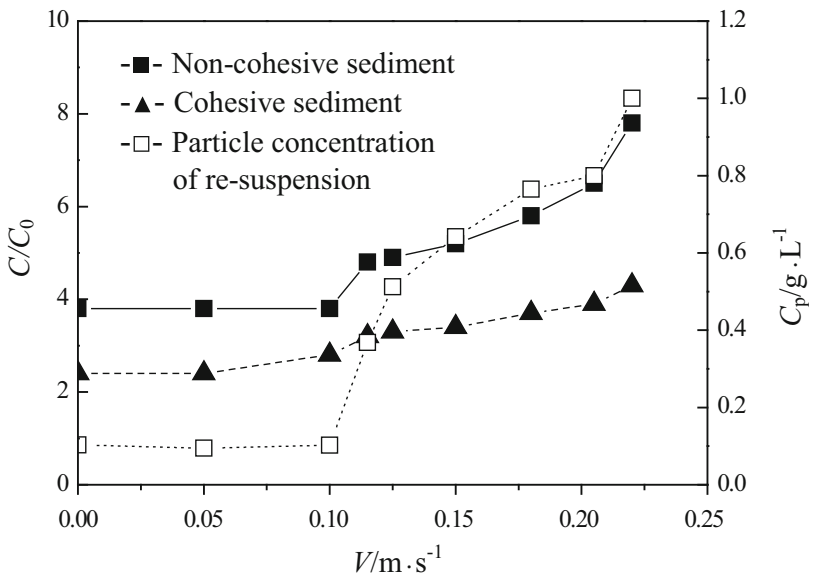

Fig. 2 The $C / C_{0}$ changes with velocity in the experiment

ther analysis of experimental data shows that the release quantity also goes up with the increasing velocity both in non-cohesive and cohesive fine sediment; meanwhile, the release quantity in cohesive fine sediment is smaller than that in non-cohesive sediment because of adsorption/desorption. Convective diffusion dominates the contaminant release both in non-cohesive and cohesive fine sediment after resuspension $(V>0.10 \mathrm{~m} / \mathrm{s})$. It contributes more than $90 \%$ of the quantity of the total release. But in unsuspended sediment $(V<0.10 \mathrm{~m} / \mathrm{s})$, convective diffusion, molecular diffusion, and adsorption/desorption have different contributions at different times during the contaminant release process. In order to study the contribution of those three mechanisms in unsuspended non-cohesive and cohesive fine sediment, the range of seepage boundary layers in sediment can be defined by convective diffusion below the water-sediment interface. Generally, convective diffusion is mainly influenced by flow shear, and the range of seepage boundary layer in non-cohesive sediment increases linearly with flow shear above the water-sediment interface, but that boundary layer of cohesive sediment has different scope because of adsorption/desorption. So the contribution of these three mechanisms in the seepage boundary layer will be analyzed as follows by numerical simulation.

\section{The couple model of contaminant release}

The velocity of overlying water brings shear force to the sediment-water interface, and then the shear force enhances seepage velocity in sediment. The contamination release could be promoted with faster seepage velocity by stronger convective and a larger concentration gradient. At the same time, the sediment adsorption/desorption influences the contaminant release in different concentrations too. Therefore, based on the N-S equation, the Darcy equation, the SoluteTransport equation and the Langmuir equation, the coupled 
mathematical model can be established for the contaminant release process.

\subsection{The coupled model}

(1) Contaminant transport equation Considering the adsorption of sediment, the transport equation can be expressed as the following

$\theta \frac{\partial C}{\partial t}+\rho_{\mathrm{b}} \frac{\partial C}{\partial t}\left(\frac{\partial C_{\mathrm{p}}}{\partial C}\right)+\nabla \cdot(-\theta D \nabla C)=-u \cdot \nabla C$,

where $\theta$ is the porosity, $C$ is the concentration of $\mathrm{P}, C_{\mathrm{p}}$ is the adsorptive concentration of $\mathrm{P}$ on sediment, $D$ is the diffusion coefficient, $D_{\mathrm{L}}$ is the diffusion coefficient of $Y$ direction $\left(D_{\mathrm{L}}=\alpha_{\mathrm{L}} v+D_{\mathrm{d}}\right), D_{\mathrm{T}}$ is the diffusion coefficient of $X$ direction $\left(D_{\mathrm{T}}=\alpha_{\mathrm{T}} u+D_{\mathrm{d}}\right), \alpha_{\mathrm{L}}$ is the dispersivity in the $Y$ direction and $\alpha_{\mathrm{T}}$ is the dispersivity in the $X$ direction. $D_{\mathrm{d}}$ is the coefficient of molecular diffusion.

In general, the contaminant adsorption/desorption characteristics of the sediment are according to the Langmuir equation as follows.

$C_{\mathrm{p}}=\frac{S K C}{1+K C}$,

where $C_{\mathrm{p}}$ is the adsorptive concentration of $\mathrm{P}$ on sediment, $K$ is the adsorption coefficient, $S(\mathrm{mg} / \mathrm{g})$ is the maximum sorption, and $C$ is the concentration of $\mathrm{P}$. So $\frac{\partial C_{\mathrm{p}}}{\partial C}=\frac{S K}{(1+K C)^{2}}$ can be obtained, which is used in Eq. (1).

(2) Darcy equation

$$
\begin{aligned}
\nabla \cdot U_{\mathrm{dr}} & =0, \\
U_{\mathrm{dr}} & =-\frac{\kappa}{\mu}(\nabla p+\rho g \nabla H),
\end{aligned}
$$

where $U_{\mathrm{dr}}$ is the velocity of Darcy, $\rho$ is the density of the fluid, $\kappa$ is the permeability of sediment, $\mu$ is the viscosity of the fluid, $p$ is the pressure, $g$ is the magnitude of gravitational acceleration, and $\nabla H$ is a unit vector in the direction over which $g$ acts.

(3) $\mathrm{N}-\mathrm{S}$ equation

$$
\begin{aligned}
& \nabla \cdot U_{\mathrm{ns}}=0, \\
& \frac{\partial U_{\mathrm{ns}}}{\partial t}+\left(U_{\mathrm{ns}} \cdot \nabla\right) U_{\mathrm{ns}}=-g \nabla h-\frac{1}{\rho} \nabla p+\frac{\mu}{\rho} \nabla^{2} U_{\mathrm{ns}},
\end{aligned}
$$

where $U_{\mathrm{ns}}$ is the velocity of $\mathrm{N}-\mathrm{S}, p$ is the pressure, and $\rho$ is the density of the fluid.

Based on the finite element method, the standard $k-\varepsilon$ model can be chosen to solve Eq. (4), and the UMPACK solver

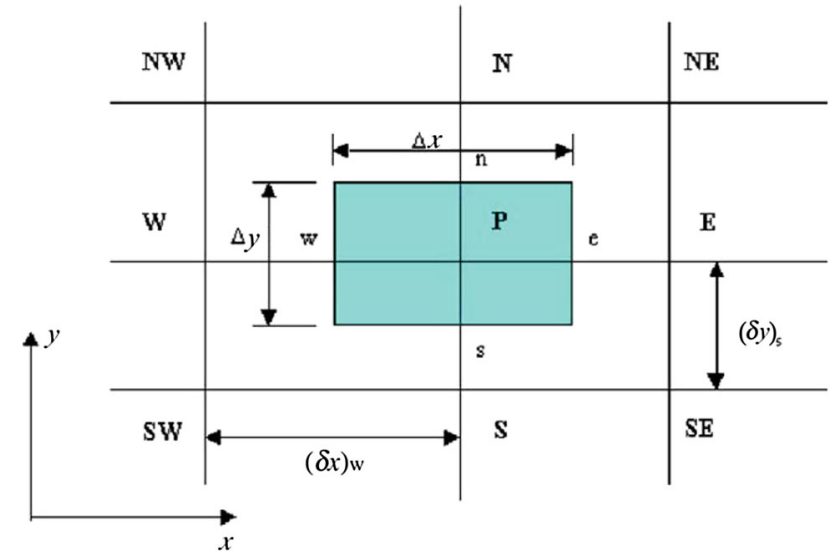

Fig. 3 The schematic diagram of control unit

for a sparse matrix can be used for calculating the small or medium-sized fluid-flow problems, so it is chosen to calculate the coupling velocity field of the overlying water column and sediment. After calculating the steady velocity field, the contaminant transport equation can be calculated for that velocity field by using the finite element method.

As shown in Fig. 3, The discretization form of the contaminant transport equation can be expressed as Eqs. (5)-(8).

$$
\begin{aligned}
& \int_{\mathrm{s}}^{\mathrm{n}} \int_{\mathrm{w}}^{\mathrm{e}} \frac{\partial C}{\partial x} \mathrm{~d} x \mathrm{~d} y=\frac{\Delta x \Delta y}{\Delta t}\left(C_{\mathrm{P}}^{t+\Delta t}+C_{\mathrm{P}}^{t}\right), \\
& \int_{\mathrm{s}}^{\mathrm{n}} \int_{\mathrm{w}}^{\mathrm{e}} \frac{\partial}{\partial x}\left(D_{x x} \frac{\partial C}{\partial x}\right) \mathrm{d} x \mathrm{y} \\
& =D_{x x} \Delta y\left(\frac{C_{\mathrm{E}}^{t+\Delta t}-C_{\mathrm{P}}^{t+\Delta t}}{\delta x_{\mathrm{e}}}-\frac{C_{\mathrm{P}}^{t+\Delta t}+C_{\mathrm{W}}^{t+\Delta t}}{\delta x_{\mathrm{w}}}\right), \\
& \int_{\mathrm{s}}^{\mathrm{n}} \int_{\mathrm{w}}^{\mathrm{e}} \frac{\partial}{\partial y}\left(D_{y y} \frac{\partial C}{\partial y}\right) \mathrm{d} x \mathrm{~d} y \\
& =D_{y y} \Delta x\left(\frac{C_{\mathrm{N}}^{t+\Delta t}-C_{\mathrm{P}}^{t+\Delta t}}{\delta y_{\mathrm{n}}}-\frac{C_{\mathrm{P}}^{t+\Delta t}+C_{\mathrm{S}}^{t+\Delta t}}{\delta y_{\mathrm{s}}}\right) \\
& \int_{\mathrm{s}}^{\mathrm{n}} \int_{\mathrm{w}}^{\mathrm{e}} \frac{\partial u C}{\partial x} \mathrm{~d} x \mathrm{~d} y=\frac{1}{2} \Delta y\left(\begin{array}{l}
u_{\mathrm{e}} C_{\mathrm{P}}^{t+\Delta t}+\left|u_{\mathrm{e}}\right| C_{\mathrm{P}}^{t+\Delta t}+u_{\mathrm{e}}^{t+\Delta t}-\left|u_{\mathrm{e}}\right| C_{\mathrm{E}}^{t+\Delta t} \\
-u_{\mathrm{w}} C_{\mathrm{W}}^{t+\Delta t}-\left|u_{\mathrm{w}}\right| C_{\mathrm{W}}^{t+\Delta t} \\
-u_{\mathrm{w}} C_{\mathrm{P}}^{t+\Delta t}+\left|u_{\mathrm{w}}\right| C_{\mathrm{P}}^{t+\Delta t}
\end{array}\right) .
\end{aligned}
$$

\subsection{Geometrical model, boundary conditions and initial conditions}

Because of the uniformity of contaminant release along the width of the flume, the $2 \mathrm{D}$ geometric model can be built to simulate the process of release near the sediment-water interface. The 2D geometric model is shown in Fig. 2, water is above the interface, the thickness is $3 \mathrm{~cm}$, and it can be defined as having a characteristic length $(d)$ to calculate the 


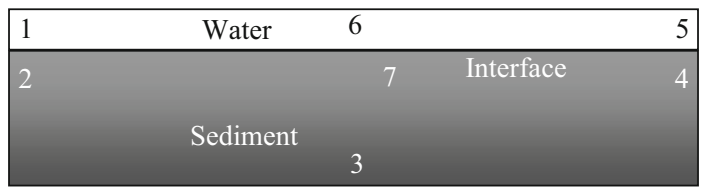

Fig. 4 Geometrical model

Reynolds number by $R e=\rho U_{\mathrm{ns}} d / \mu$. Sediment is below the interface, the thickness is $10 \mathrm{~cm}$. The length of the model is $50 \mathrm{~cm}$, and it can be meshed with quadrilateral elements. In the channel experiment, the ratio of depth between water and sediment is three. In numerical simulations, the velocity field and concentration field in sediment are mainly researched, so the depth of water is set as $3 \mathrm{~cm}$ to reduce the amount of the calculation, and the top boundary of water is set as a symmetrical boundary condition (Fig. 4).

The coefficient of molecular diffusion $\left(D_{\mathrm{d}}\right)$ is $2.3 \times$ $10^{-5} \mathrm{~m}^{2} / \mathrm{s}$ by experimental calibration, $\alpha_{\mathrm{L}}$ is $0.005 \mathrm{~m}, \alpha_{\mathrm{T}}$ is $0.001 \mathrm{~m}$, and the tortuosity factor is 0.7 . The initial concentration of sediment is $C_{0}=100 \mathrm{mg} / \mathrm{l}$. According to experimental results, the porosity of $D_{0}$ is 0.48 , its maximum sorption $(S)$ is $0.793 \mathrm{mg} / \mathrm{g}$, and its adsorption coefficient $(K)$ is 1.198 .

Boundary conditions:

(1) Boundary conditions of Darcy: 2 and 4 are symmetrical boundary conditions, 3 is a wall boundary condition.

(2) Boundary conditions of N-S: 1 is the inlet boundary condition; the velocity is $0.01 \mathrm{~m} / \mathrm{s}\left(V_{1}\right), 0.05 \mathrm{~m} / \mathrm{s}\left(V_{2}\right)$ and $0.1 \mathrm{~m} / \mathrm{s}\left(V_{3}\right)$, the turbulence intensity is $5 \%$, the turbulence length scale is $0.03 \mathrm{~m} .5$ is the outlet boundary condition. 6 is the symmetrical boundary condition.

(3) Boundary conditions of concentration transport:1, 2, 3, 4 , and 5 are flux boundary conditions, the flux of concentration is zero. 6 is the symmetry boundary condition.

(4) Interface is 7, $U_{\mathrm{ns}}=U_{\mathrm{dr}}, P_{\mathrm{ns}}=P_{\mathrm{dr}}$.

\section{Results}

Generally, the velocity gradient of water flow can cause shear stress near the interface; variable shear stress can cause different seepage velocity in sediment, and then it will influence the release flux of contamination. The adsorption/desorption will also influence the concentration of contamination during this process in sediment. In order to research the release mechanisms in un-suspended sediment, the coupled model can be used under $V_{1}(0.01 \mathrm{~m} / \mathrm{s}), V_{2}(0.05 \mathrm{~m} / \mathrm{s})$ and $V_{3}(0.10 \mathrm{~m} / \mathrm{s})$, and $V_{3}$ is very close to the critical incipient velocity for fine sediment suspension in this paper. As shown in Fig. 5, $C$ is the concentration of contamination, $C_{0}$ is the initial concentration of contamination, and $T$ is the time of contamination

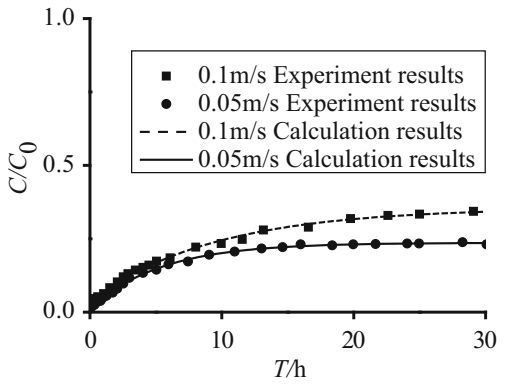

Fig. 5 The $C / C_{0}$ in the experiment and calculations

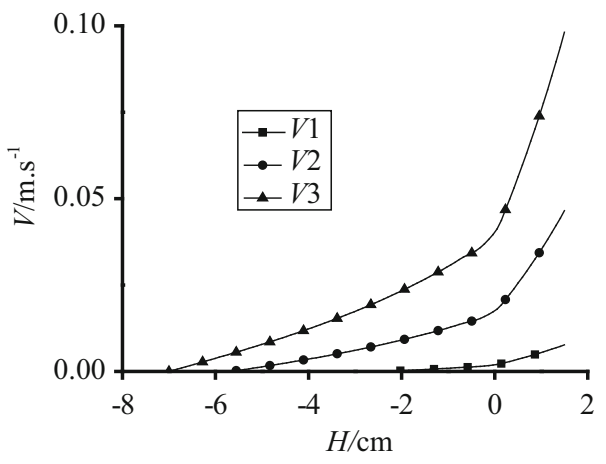

Fig. 6 The velocity changing with depth in the sediment

release. The concentration goes up with time increase, and it reaches the equilibrium concentration after $20 \mathrm{~h}$. The calculation results agree well with the experimental results under $V_{2}$ and $V_{3}$. It can verify the rationality of coupled models. As shown in Fig. 6, $\mathrm{H}$ is the depth from water $(H>0)$ to sediment $(H<0)$, the location 0 is the interface between water and sediment, the velocity in sediment decreases with the depth increase, the gradient of velocity reaches a peak value near the interface, and then the shear force reaches a peak value at the same place.

The contaminant release from a static sediment layer into the overlying water column is a typical mass transfer process above the sediment-water interface. In this case, the contaminant concentration variation of the overlying water column is related to the supply of the contaminants from the sediment, including the desorption from the uppermost sediment, the molecular diffusion from the pore water, and the convective diffusion by velocity gradient. The seepage boundary layer can be defined as a range of sediment in which concentration is influenced by convective diffusion. When the velocity is near the critical incipient velocity, the depth of the seepage boundary layer may reach the maximum in unsuspended sediment. In order to research the relationship between the depth of that boundary and the velocity of the overlying water, the concentration and its flux of contaminant are analyzed at location $h_{1}, h_{2}$, and $h_{3}, h_{1}$ is $1 \mathrm{~cm}$ below the interface, $h_{2}$ is $3 \mathrm{~cm}$ below the interface, and $h_{3}$ is $5 \mathrm{~cm}$ below the interface. 


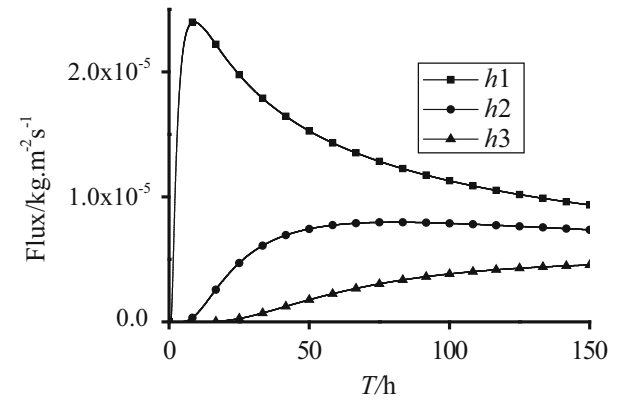

Fig. 7 The flux changing with time under $V_{3}$

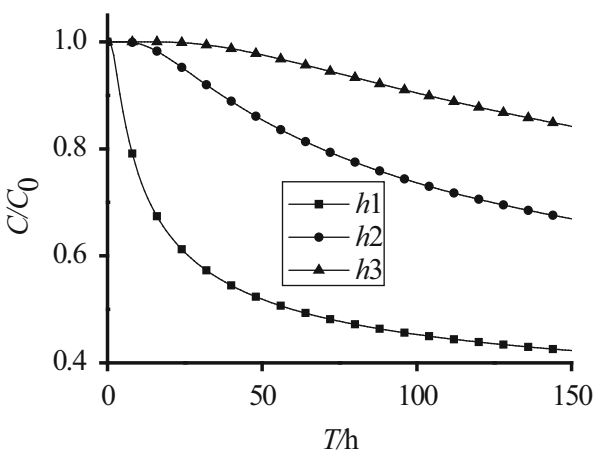

Fig. 8 The $C / C_{0}$ changing with time under $V_{1}$

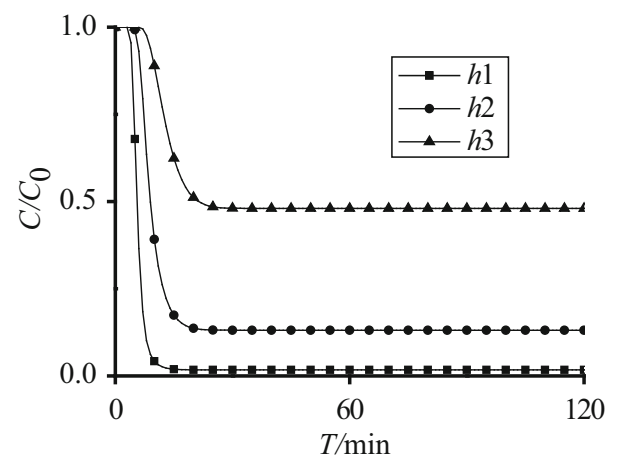

Fig. 9 The $C / C_{0}$ changing with time under $V_{3}$

As shown in Fig. 7, the release flux reaches a peak value in 12 hours at $h_{1}$, and then the flux goes down with time increasing. The release flux continually increases with time at $h_{2}$ and $h_{3}$. In the initial stage of release, the contaminant mainly releases via convective diffusion and desorption from $h_{1}$; the flux is about 10 to 100 times larger than that of $h_{2}$ and $h_{3}$. In the middle stage, there is a larger concentration gradient between $h_{1}$ and $h_{2}$, thus the influence of molecular diffusion gradually becomes more and more important. Finally, the flux of $h_{1}, h_{2}$ and $h_{3}$ are close to each other.

As show in Fig. 8, the concentration of $h_{1}$ goes down after $20 \mathrm{~min}$ and reaches balance after 150 hours under low velocity $\left(V_{1}\right)$, and it rapidly goes down at the beginning and reaches the concentration balance in $30 \mathrm{~min}$ under high velocity $\left(V_{3}\right)$

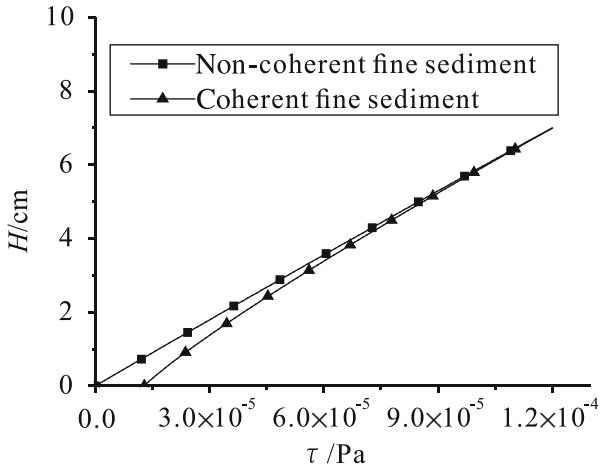

Fig. 10 The depth of seepage boundary changing with shear stress

as shown in Fig. 9. Convective diffusion is about 10-50 times larger than molecular diffusion during the initial stages under high velocity, and it is close to molecular diffusion in later stages. But convective diffusion is about 6 times larger than molecular diffusion during the initial stages under low velocity, and it is about a quarter of the molecular diffusion in later stages, and has a similar level with desorption. The contaminant releases mainly via convective diffusion under higher velocity, and it is mainly via molecular diffusion and desorption under lower velocity.

In flume experiments, the characteristics of contaminant release from resuspended sediment and unsuspended sediment are researched by using different particle diameters of sediment. In coarse sediment and non-coherent fine sediments, the contaminant releases mainly via convective diffusion under resuspension conditions, and it is mainly via convective diffusion and molecular diffusion under unsuspended conditions, because of its lower adsorption/desorption. In coherent fine sediment, the contaminant releases mainly via convective diffusion under resuspension conditions. The phenomenon is similar to coarse sediment and non-coherent fine sediment, but the contaminant release is a more complex process under unsuspended condition.

With increasing velocity of overlying water, the shear stress goes up near the interface, and then the convective diffusion in sediments could be enhanced at the same time. Following enhanced convective diffusion, the concentration of contaminants in pore water goes down rapidly, the contaminant is gradually desorbed from sediment by decreasing concentration in the pore water. So, the desorption of coherent fine sediment enhances the concentration in pore water, and it weakens the concentration gradient in pore water. The molecular diffusion is also weakened at the same time, and the flux of contaminant release goes down. Under the lower velocity of flow, that phenomenon is more obvious.

Generally, convective diffusion is mainly influenced by flow shear, and the range of seepage boundary layer in non-cohesive sediment increases linearly with flow shear above the water-sediment interface. As shown in Fig. 10, in 
non-cohesive fine sediment, the maximum value of seepage boundary is about $7 \mathrm{~cm}$, and the depth of seepage boundary changes linearly with the shear stress near the interface. In cohesive fine sediment, the maximum value of seepage boundary is also about $7 \mathrm{~cm}$, but the depth of seepage boundary changes nonlinearly with the shear stress. Under lower shear stress conditiosn, the desorption of coherent fine sediment strongly weakens the concentration gradient in pore water, and it also reduces the release flux of contaminants in convective diffusion. Then the range of seepage boundary decreases during that process, which is directly influenced by convective diffusion. Finally, the depth of seepage boundary in cohesive sediment is different from that in non-cohesive sediments.

\section{Conclusion}

The characteristics of contaminant release from fine sediment to overlying water are experimentally and numerically investigated under different flow velocities. Conclusions can be summarized as follows:

(1) The obtained experimental data in terms of the adsorption quantity and the aqueous equilibrium concentration for cohesive sediment fit well with the Langmuir equation. The fine sediment $\left(D_{90}=0.06 \mathrm{~mm}\right)$ has more significant environmental effects because of its stronger adsorption and flocculating behaviors. The flume experiment results show that convective diffusion dominates the contaminant release both in non-cohesive and cohesive fine sediment after its resuspension, which contributes more than $90 \%$ of the total release. Compared with sediment in unsuspension and resuspension, molecular diffusion and desorption have more contribution for contaminant release from unsuspended sediments.

(2) Because of the coupling effect in overlying water, with the seepage known and the concentration known, a coupled mathematical model could be established for contaminant release from sediment to water. The calculation results are close to experimental results; it can verify the rationality of that model. Convective diffusion is about 10-50 times larger than molecular diffusion and desorption during the initial stages under high velocity, then it is close to molecular diffusion in later stages. Desorption and adsorption have dynamic conversion in later stages followed by equilibrium concentration. Convective diffusion is about 6 times larger than molecular diffusion during the initial stages under low velocity, it is about a quarter of molecular diffusion in later stages, and has a similar level with desorption/adsorption.

(3) For non-cohesive unsuspended sediment, the contamination release is mostly influenced by convective diffusion and molecular diffusion; the depth of seepage boundary layer has a nearly linear relationship with the shear stress. Because of desorption/adsorption changing the influence range of convective diffusion, the depth of seepage boundary in cohesive sediments is different from that in non-cohesive sediment. The phenomenon is more obvious under the lower shear stress.

Acknowledgments This work was supported by the National Key Program of the National Natural Science Foundation of China (Grant 11032007)

\section{References}

1. Schindler, D.W., Hecky, R.E.: Eutrophication: More nitrogen data needed. Science 324, 721 (2009)

2. Sundareshwar, P.V., Morris, J.T., Koepfler, E.K., et al.: Phosphorus limitation of coastal ecosystem processes. Science 299, 563-565 (2003)

3. Kim, L.H., Choi, E., Stenstrom, M.K.: Sediment characteristics, phosphorus types and phosphorus release rates between river and lake sediment. Chemosphere 50, 53-61 (2003)

4. Fries, J.S.: Predicting interfacial diffusion coefficients for fluxes across the sediment-water interface. J. Hydraul. Eng. 133, 267272 (2007)

5. Uncles, R.J., Stephens, J.A., Law, D.J.: Turbidity maximum in the macrotidal, highly turbid Humber Estuary, UK: Flocs, fluid mud, stationary suspensions and tidal bores. Estuar. Coast. Shelf Sci. 67, 30-52 (2006)

6. Liang, D., Wangb, X., Bockelmann-Evans, B.N.: Study on nutrient distribution and interaction with sediment in a macro-tidal estuary. Adv. Water Resour. 52, 207-220 (2013)

7. Yoon, H.-D., Cox, D.T., Kim, M.: Prediction of time-dependent sediment suspension in the surf zone using artificial neural network. Coast. Eng. 71, 78-86 (2013)

8. Hooper, T., Austen, M.: Tidal barrages in the UK: Ecological and social impacts, potential mitigation, and tools to support barrage planning. Renew. Sustain. Energy Rev. 23, 289-298 (2013)

9. Jin, X., He, Y., Kirumba, G.: Phosphorus fractions and phosphate sorption-release characteristics of the sediment in the Yangtze River estuary reservoir. Ecol. Eng. 55, 62-66 (2013)

10. Chatelain, M., Guizien, K.: Modelling coupled turbulence: Dissolved oxygen dynamics near the sediment-water interface under wind waves and sea swell. Water Res. 44, 1361-1372 (2010)

11. O'Connor, B.L., Harvey, J.W.: Scaling hyporheic exchange and its influence on biogeochemical reactions in aquatic ecosystems. Water Resour. Res. 44, 1-17 (2008)

12. Packman, A.I., Marion, A., Zaramella, M., et al.: Development oflayered sediment structure and its effects on pore water transport and hyporheic exchange. Water Air Soil Pollut. 6, 433-442 (2006)

13. Hoeg, S., Scholer, H.F., Warnatz, J.: Assessment of interfacial mass transfer in water-unsaturated soils during vapor extraction. J. Contam. Hydrol. 74, 163-195 (2004)

14. Zhu, H., Cheng, P., Zhong, B., et al.: The mechanisms of contaminants release due to incipient motion at sediment-water interface. Sci. China Phys. Mech. Astron. 24, 589-594 (2012)

15. Couceiro, F., Turner, A., Millward, G.E.: Adsorption and desorption kinetics of rhodium (III) and platinum (IV) in turbid suspensions: Potential tracers for sediment transport in estuarine flumes. Mar. Chem. 107, 308-318 (2007)

16. Cao, S., Cheng, B., Wang, Q., et al.: Characterization and mechanism of zinc salts as tanning agents. JALCA 108, 428-433 (2013) 
17. Corbett, D.R.: Resuspension and estuarine nutrient cycling: Insights from the Neuse River Estuary. Biogeosci. Discuss. 7, 2767-2798 (2010)

18. Mesnage, V., Ogier, S., Bally, G., et al.: Nutrient dynamics at the sediment-water interfacein a Mediterranean lagoon (Thau, France): Influence of biodeposition by shellfish farming activities. Mar. Environ. Res. 63, 257-277 (2007)

19. Heggie, D.T., Logan, G.A., Smith, C.S., Fredericks, D.J., Palmer, D.: Biogeochemical processes at the sediment-water interface, Bombah Broadwater, Myall Lakes. Hydrobiologia 608, 49-67 (2008)

20. Ma, F., Jiang, C., Bo Rauen, W.B., et al.: Modelling sediment transport processes in macro-tidal estuary. Sci. China Ser. E. 52, 3368-3375 (2009)
21. Cheng, P., Zhu, H., Fan, J., Fdei, M., et al.: Numerical research for contaminant release from un-suspended bottom sediment under different hydrodynamic conditions. J. Hydrodyn. 25, 620-627 (2013)

22. Kun, Z., Cheng, P., Zhong, B., et al.: Total phosphorus release from bottom sediment in flowing water. J. Hydrodyn. 24, 589-594 (2012)

23. Higashino, M., Gantzer, C.J., Stenfan, H.G.: Unsteady diffusional mass transfer at the sediment/water interface: theory and significance for SOD measurement. Water Res. 38, 1-12 (2004)

24. Orlins, J.J., Gulliver, J.S.: Turbulence quantification and sediment resuspension in an oscillating grid chamber. Exp. Fluids 34, 662677 (2003) 